\title{
Metabolic Syndrome in Subclinical and Overt Hypothyroidism
}

\author{
Buddhi Bahadur Thapa ${ }^{1}$, Madhav Tiwari², Sailesh Gurung ${ }^{2}$, Man Bahadur Gurung ${ }^{3}$, Mukunda Kalauni ${ }^{4}$, \\ Bhup Dev Bhatta 4
}

${ }^{1}$ Department of Medicine, Fewacity Hospital, Pokhara, Nepal.

${ }^{2}$ Department of Medicine, Kaski Model Hospita, Pokhara, Nepal.

${ }^{3}$ Department of Medicine, Namaste Hospital, Pokhara, Nepal.

${ }^{4}$ Biochemistry Unit, Swastik Referal Laboratory and Research Centre, Pokhara, Nepal

\section{Correspondence:}

Bhup Dev Bhatta

Biochemistry Unit, Swastik Referral

Laboratory and Research Centre,

Pokhara, Nepal

e-mail : bhattabd@gmail.com

Article recived : 6th Jan. 2018

Article accepted : 24th July 2018

\begin{abstract}
Background: Sub-clinical hypothyroidism ( $\mathrm{SCH}$ ), overt hypothyroidism and metabolic syndrome (MetS) are recognized risk factors for atherosclerotic cardiovascular disease and Type 2 diabetes mellitus (DM- II).Thyroid function affects MetS parameters including blood pressure (BP), fasting blood sugar (FBS), serum triglycerides (TG) and high density lipoprotein cholesterol (HDL-C). But the relationship between MetS and thyroid functions is yet to be identified clearly.

The present study is to investigate the frequency of MetS in patients of $\mathrm{SCH}$ and overt hypothyroidism.

Materials and Methods: A hospital based cross-sectional study was conducted at Swastik referral laboratory and research centre. In this study, 50 patients with overt hypothyroidism, 50 patients with $\mathrm{SCH}$ and 129 euthyroid controls were enrolled. National Cholesterol Education Program- Adult Treatment Panel III (NCEP-ATP III; 2005) revision criteria were used to diagnose metabolic syndrome. Thyroid function test (TFT: FT3, FT4 and TSH) was done by using chemiluminescence immunoassay (CLIA) and other tests by using a semi-auto analyzer. ANalysis Of VAriance (ANOVA) test was performed using SPSS (version 16.0).

Result: There was a significant difference in the mean of the waist circumference $(p=0.031), B P$ systolic $(p=0.010), B P$ diastolic $(p<0.001))$, FBS $(p=0.001)$, serum HDL-C $(p=0.031)$ and serum TG $(p=0.003)$ between control, subclinical and overt hypothyroidism group ( $p<0.001$ ). Prevalence of MetS was $25.6 \%$ in euthyroid controls whereas $44.0 \%$ in the $\mathrm{SCH}$ group and $62.0 \%$ in the overt hypothyroid group $(p<0.001)$.

Conclusion: Thyroid dysfunction may be responsible for the development of metabolic syndrome.
\end{abstract}

Keywords: Metabolic syndrome, overt hypothyroidism, subclinical hypothyroidism.

\section{INTRODUCTION}

Herman Haller in 1977 used the term "Metabolic Syndrome" (MetS) but this concept was established by Reavan. In 1988, Reaven noted that insulin insensitivity leads to dyslipidemia, hyperglycemia and hypertension. All of these are associated with increased risk of coronary artery disease (CAD). He called clustering of these features as Syndrome $X$. Reaven and subsequently others postulated that insulin resistance underlies Syndrome $X .{ }^{1}$ It is now agreed that the term MetS remains the most useful and widely accepted description of this cluster of metabolically related cardiovascular risk factors like DM and raised FBS, abdominal obesity, high cholesterol and high BP. ${ }^{2}$

It is estimated that around a quarter of the world's adult population have MetS. ${ }^{3}$ Prevalence of MetS in Indian population is $33.5 \%$ (24.9\% in males, $43.2 \%$ in females). In another study conducted in urban Karnataka $(n=1178)$, prevalence of MetS was $22.3 \%$ ( $25 \%$ in males and $22 \%$ in females) among the adult population. ${ }^{4}$

Among MetS patients, possibility of death is almost double and possibility of heart attack and stroke is almost triple fold compared to those without MetS. ${ }^{5}$ On the other hand, MetS increase the risk of developing DM-II by five times, compared to non-MetS individuals. ${ }^{3}$ The clustering of cardio vascular disease 
(CVD) risk factors that typifies the MetS is considered to be the driving force for a CVD epidemic. ${ }^{6}$

Hypothyroidism is caused by decreased production of thyroid hormone causing subnormal concentration of circulating thyroid hormone. ${ }^{7}$ Third National Health and Nutrition Examination Survey (NHANES III) showed a $4.6 \%$ prevalence of hypothyroidism in the general population, while $9.5 \%$ of the study population had $\mathrm{SCH} .{ }^{8}$ Since thyroid hormones play essential role in regulating energy balance, metabolism of glucose and lipids, it affects MetS parameters including HDL-C, TG, BP and plasma glucose. Hypothyroid patients have increased levels of total cholesterol (TC) and low density cholesterol (LDL). ${ }^{8}$

$\mathrm{SCH}$ is a condition in which circulating TSH level elevates with free T4 concentrations at the lower end of the euthyroid range. ${ }^{8} \mathrm{SCH}$ affects approximately $4-10 \%$ of the general population. ${ }^{9} \mathrm{SCH}$ has been shown to be associated with more severe CAD. ${ }^{10}$ Several studies suggest that mortality and morbidity are higher in younger patients with both ischemic heart disease and $\mathrm{SCH} .{ }^{11}$ Both MetS and hypothyroidism are independent risk factors for CVD and presence of both conditions may be responsible for increased risk of CVD. A considerable overlap occurs in the pathogenic mechanisms of atherosclerotic cardiovascular disease, MetS and hypothyroidism. ${ }^{12}$

However the association between thyroid dysfunction and components of MetS is still debatable. ${ }^{13}$ Thyroid dysfunction is common in Nepal, and the prevalence of DM and MetS has been rising steadily. It has been reported that $20.7 \%$ of the Nepalese population have MetS based on NCEP-ATP III criteria. ${ }^{14}$ There is inadequate and scanty data in the context of our settings regarding the relationship between thyroid status and MetS. This study was undertaken to investigate and compare the frequency of MetS in $\mathrm{SCH}$ and overt hypothyroid patients.

\section{MATERIALS AND METHODS}

A hospital based cross-sectional study was carried out in the Biochemistry Unit of Swastik Referral Laboratory and Research Centre, Kaski Model Hospital, Namaste Hospital and Research Centre and Fewacity Hospital, Pokhara. Ethical approval was taken from respective hospitals and laboratories. The study was carried out from 1st January 2015 to 20th July 2017. Written consent was obtained from all the participants. All the blood samples (10-12 hour fasting) were collected and serum samples were analyzed for TFT by using CLIA. Patients with TSH level within 0.4- $4.5 \mu \mathrm{lU} / \mathrm{ml}$, fT4 level within $0.89-1.72 \mu \mathrm{g} / \mathrm{dl}$ and fT3 level within $1.21-4.2 \mathrm{pg} /$ $\mathrm{ml}$ were taken as euthyroid (control group). Patients with TSH level $>4.5 \mu \mathrm{IU} / \mathrm{ml}$ and normal fT3 and fT4 level were classified as $\mathrm{SCH}$. Patients with TSH level $>4.5 \mu \mathrm{lU} / \mathrm{ml}$ and fT4 level $<0.89 \mu \mathrm{g} / \mathrm{dl}$, fT3 level $<1.2$ $\mathrm{pg} / \mathrm{ml}$ were classified as overt hypothyroidism.

Euthyroid and hypothyroid patients (subclinical and overt) were further examined as per NCEP ATP III criteria. Patients with known diabetes or other endocrine disorders, pregnancy, renal diseases, liver diseases, known cases of hypothyroidism, history of thyroidectomy, receiving steroid, lipid lowering agent, oral contraceptives were excluded. FBS, TG, HDL-C, Systolic Blood Pressure (SBP), Diastolic Blood Pressure (DBP) and waist circumference were measured.

FBS was estimated by enzymatic method Glucose Oxidase and Peroxidase (GOD-POD), TG was estimated by GPO-PAP method and HDL-C was estimated by using precipitation and CHOD-PAP method. Free T3, Free T4 and TSH were estimated by CLIA. Blood pressure (BP) was measured after 10 minutes of rest. A second measurement was made after 3 minutes. The mean of two measurements was taken for SBP and DBP. Waist circumference was measured by measuring tape.

\section{RESULTS}

A total of 229 subjects, 95 (41.4\%) males and 134 $(58.6 \%)$ females were enrolled. 129 subjects were controls (euthyroid), 50 were subclinical hypothyroid and 50 were overt hypothyroid.

The mean age of the study group was $45 \pm 11.6$

Table 1.

\begin{tabular}{|lllll|}
\hline Parameters & Euthyroid & $\begin{array}{l}\text { Subclinical } \\
\text { hypothy- } \\
\text { roid } \\
\mathrm{N}=129\end{array}$ & $\begin{array}{l}\mathrm{N}=50 \\
\text { Overthypo- } \\
\text { mean } \pm \mathrm{SD}\end{array}$ & $\begin{array}{c}\mathbf{P} \\
\text { value }\end{array}$ \\
\hline $\begin{array}{l}\text { Waist circumfer- } \\
\text { ence }(\mathrm{cm})\end{array}$ & $93.8 \pm 8.3$ & $90.5 \pm 8.6$ & $94.5 \pm 8.1$ & 0.031 \\
\hline FBS $(\mathrm{mg} / \mathrm{dl})$ & $97.4 \pm 27.5$ & $95.2 \pm 16.1$ & $112.1 \pm 25.5$ & 0.001 \\
\hline TG (mg/dl) & $141.6 \pm 59.7$ & $181.7 \pm 97.5$ & $287.4 \pm 473.5$ & 0.003 \\
\hline $\begin{array}{l}\mathrm{HDL}-\mathrm{C} \\
(\mathrm{mg} / \mathrm{dl})\end{array}$ & $49.1 \pm 7.6$ & $47.7 \pm 5.9$ & $46.0 \pm 6.6$ & 0.031 \\
\hline $\mathrm{SBP}(\mathrm{mmHg})$ & $120.8 \pm 15.3$ & $126.2 \pm 13.8$ & $127.4 \pm 14.8$ & 0.010 \\
\hline $\mathrm{DBP}(\mathrm{mmHg})$ & $78.7 \pm 9.8$ & $82.2 \pm 7.1$ & $84.6 \pm 8.6$ & 0.000 \\
\hline
\end{tabular}

Table 1. shows the mean values of waist circumference, SBP, DBP, TG, FBS, which were higher in sub 
clinical and overt hypothyroid compared to euthyroid (controls). HDL-C was lower in the overt hypothyroid group compared to controls which is statistically significant $(p<0.031)$.

Table 2. Prevalence of Metabolic syndrome in control group and subclinical and overt hypothyroidism

\begin{tabular}{lccc} 
& \multicolumn{2}{c}{ MetS } & P-value \\
& Non MetS & MetS present & \\
group control Count & 96 & 33 & $<0.01$ \\
\hline \% within group & $74.4 \%$ & $25.6 \%$ & \\
\hline subclinical Count & 28 & 22 & \\
\hline \% within group & $56.0 \%$ & $44.0 \%$ & \\
\hline overt hypo Count & 19 & 31 & \\
\% within group & $38.0 \%$ & $62.0 \%$ &
\end{tabular}

Table 2 shows the overall prevalence of MetS in study subjects was found to be $37.6 \%$. The prevalence of Mets found in euthyroid subjects, $\mathrm{SCH}$ and overt hypothyroid was $25.6 \%, 44.0 \%$ and $62.0 \%$ respectively. Frequency of MetS in overt hypothyroidism was higher in comparison to $\mathrm{SCH}$.

Table 3. Comparisons between the variables of subclinical and overt hypothyroidism

\begin{tabular}{|c|c|c|c|}
\hline \multirow[t]{3}{*}{ Parameters } & Subclinical hypothyroid & Overt hypothyroid & \multirow[t]{2}{*}{$P$ value } \\
\hline & $N=50$ & $N=50$ & \\
\hline & mean $\pm S D$ & mean $\pm S D$ & \\
\hline \multicolumn{2}{|c|}{ Waist circumference $(\mathrm{cm}) 90.5 \pm 8.6$} & $94.5 \pm 8.1$ & 0.019 \\
\hline FBS (mg/dl) & $95.2 \pm 16.1$ & $112.1 \pm 25.5$ & $<0.001$ \\
\hline TG $\quad(m g / d l)$ & $181.7 \pm 97.5$ & $287.4 \pm 473.5$ & 0.126 \\
\hline HDL-C (mg/dl) & $47.7 \pm 5.9$ & $46.0 \pm 6.6$ & 0.195 \\
\hline $\mathrm{SBP}(\mathrm{mmHg})$ & $126.2 \pm 13.8$ & $127.4 \pm 14.8$ & 0.693 \\
\hline $\mathrm{DBP}(\mathrm{mmHg})$ & $82.2 \pm 7.1$ & $84.6 \pm 8.6$ & 0.132 \\
\hline
\end{tabular}

Table 3. shows the mean TG, SBP \& DBP were higher in overt hypothyroid group in comparison to $\mathrm{SCH}$ but not significantly different between the two groups. However, waist circumference was significantly correlated between the two groups $(p=0.019)$ which was higher in overt hypothyroidism. Comparisons of FBS between the groups were done by independent test. FBS was higher in overt hypothyroid group as compared to $\mathrm{SCH}$ group which were statistically significant $(p=<0.001)$.

\section{DISCUSSION}

Hypothyroidism and MetS are recognized risk factors for atherosclerotic cardiovascular disease. Subclinical and overt hypothyroidism had unfavorable effects on biochemical parameters. ${ }^{15}$ Environmental and genetic factors also affect MetS. ${ }^{16}$

Our study found that waist circumference was higher in subclinical and overt hypothyroid group in comparison to euthyroid group. Waist circumference was statistically significant during the comparison between subclinical and overt hypothyroid groups $(p=0.019)$ and this finding correlates with Mehmet Erdogan findings. ${ }^{5}$ Another study reported that Waist circumference was larger in the hypothyroid MetS patients than in the $\mathrm{SCH}$ group and controls. ${ }^{17}$ Our study found significantly higher FBS levels in subclinical and overt hypothyroid subjects. Similar study by Maratouet $\mathrm{al}^{17}$ and Ganidagly et al ${ }^{18}$ found significantly higher FBS levels in hypothyroid patients. Raised SBP and DBP were observed in our study but it was not statistically significant. A study in Bangladesh reported that about half of the individual in both the subclinical and overt hypothyroid groups had increased SBP and DBP. Only one fifth of euthyroid subjects had raised BP. ${ }^{19}$

Serum TG was found to be lower in euthyroid group than subclinical and overt hypothyroid group. Our study found that serum TG levels were significantly increased in overt hypothyroid group compared to $\mathrm{SCH}$ group and euthyroid group $(\mathrm{p}=0.003)$.

$R$ Haque found that serum TG levels were significantly increased in hypothyroid patients than euthyroid group..$^{19}$ These findings are similar to the findings from our study. Another study Ruhla Salso reported that a high TG was observed in MetS patients. ${ }^{20}$

Our study found that the mean serum HDL-C was significantly decreased in subclinical and overt hypothyroid group compared to euthyroid subjects, which is similar to the finding of Althas et al. ${ }^{21}$

This study found metabolic syndrome in about $25.6 \%$ in control group, $44.0 \%$ in $\mathrm{SCH}$ and $62.0 \%$ in overt hypothyroid subjects. The overall prevalence of MetS was found to be $37.6 \%$. Uzunlulu et al found that the prevalence of MetS was $53.6 \%$ (40.7\% in females and $12.9 \%$ in males). ${ }^{15}$ Another study in Bangladesh found that $27 \%$ of the euthyroid subjects had MetS according to modified NCEP- ATP III criteria which is closer to our study. ${ }^{19} \mathrm{~A}$ study done in rural community of Bangladesh found that $20.7 \%$ of the population had MetS .22 Another study reported by $R$ Haque found $82.5 \%$ had MetS in hypothyroid subjects. ${ }^{19}$ MetS frequency was found similar in both subclinical (81.2\%) and overt hypothyroidism (83.8\%). ${ }^{19}$ Ganidagly et 
al reported that $44 \%$ of the hypothyroid, $35 \%$ of the $\mathrm{SCH}$ had MetS. ${ }^{18}$ MetS prevalence was $44 \%$ in the hypothyroid group, $35 \%$ in the $\mathrm{SCH}$ group and $33 \%$ in the control group. ${ }^{1}$

\section{CONCLUSION}

MetS prevalence was higher in subclinical and overt hypothyroid subjects. Our study suggests that all hypothyroid patients should be screened for MetS to reduce mortality rate due to cardio metabolic complications.

\section{ACKNOWLEDGEMENT}

We are thankful to Dr. Prakash Thapa for his valuable support in statistical analysis. We also wish to thank Ms. Bijita Thapa and Mr. Dhananjaya Paudel for their help in data collection and sample analysis.

\section{REFERENCES}

1. Reaven GM. Role of insulin resistance in human disease. Diabetes. 1988 Dec 1;37(12):1595-607.

2. Alberti KG, Zimmet P, Shaw J. The metabolic syndrome a new worldwide definition. The Lancet. 2005 Sep 24;366 (9491): 1059-62.

3. Stern MP, Williams K, González-Villalpando C, Hunt KJ, Haffner SM. Does the metabolic syndrome improve identification of individuals at risk of type 2 diabetes and/or cardiovascular disease? Diabetes care. 2004 Nov 1;27(11):2676-81.

4. Godwa V. Subclinical Thyroid dysfunction in subjects with metabolic syndrome. Journal of Biotechnology and Biochemistry.2016;2(II):6.

5. Isomaa BO, Almgren P, Tuomi T, Forsén B, Lahti K, Nissen M, et al. Cardiovascular morbidity and mortality associated with the metabolic syndrome. Diabetes care. 2001 Apr 1;24(4):683-9.

6. Parapid B, Ostojic MC, Lalic NM, Micic DR, Damjanovic S, Bubanja D, et al. Risk factors clustering within the metabolic syndrome: a pattern or by chance. HJC. 2014 Apr;55(2):92-100.

7. Strachan MW, Walker BR. Endocrine disease. Davidson Principles and Practice of Medicine ,London.Churchill Livingstone. 22nd ed.;2006:738-40.

8. Canaris GJ, Manowitz NR, Mayor G, Ridgway EC. The Colorado thyroid disease prevalence study. Archives of internal medicine. 2000 Feb 28;160(4):526-34.

9. Surks MI, Ortiz E, Daniels GH, Sawin CT, Col NF, Cobin RH, et al. Subclinical thyroid disease: scientific review and guidelines for diagnosis and management. JAMA. 2004 Jan 14;291(2):228-38.

10. Auer J, Berent R, Weber T, Lassnig E, Eber B. Thyroid function is associated with presence and severity of coronary atherosclerosis. Clinical cardiology. 2003 Dec 1;26(12):569-73.

11. Tseng FY, Lin WY, Lin CC, Lee LT, Li TC, Sung PK, et al. Subclinical hypothyroidism is associated with increased risk for allcause and cardiovascular mortality in adults. Journal of the American College of Cardiology. 2012 Aug 21;60(8):730-7.

12. Kota SK, Meher LK, Krishna SV, Modi KD. Hypothyroidism in metabolic syndrome. Indian Journal of Endocrinology \& Metabolism. 2012 Dec 1;16: 332-333

13. Mehran L, Amouzegar A, Tohidi M, Moayedi M, Azizi F. Serum free thyroxine concentration is associated with metabolic syndrome in euthyroid subjects. Thyroid. 2014 Nov 1;24(11):1566-74.

14. Baral N, Lamsal M, Koner BC, Koirala S. Thyroid dysfunction in eastern Nepal. Southeast Asian Journal of Tropical Medicine and Public Health. 2002 Sep 16;33(3):638-41.

15. Uzunlulu M, Yorulmaz E, Oguz A. Prevalence of subclinical hypothyroidism in patients with metabolic syndrome. Endocrine Journal. 2007;54(1):71-6.

16. Grundy SM, Cleeman JI, Daniels SR, Donato KA, Eckel RH, Franklin BA et al. Diagnosis and management of the metabolic syndrome: An American Heart Association/National Heart, Lung, and Blood Institute scientific statement. Circulation. 2005 Oct 25;112(17):2735-52.

17. Luboshitzky R, Aviv A, Herer P, Lavie L. Risk factors for cardiovascular disease in women with subclinical hypothyroidism. Thyroid. 2002 May 1;12(5):421-5.

18. Ganidagli S, ErdoganM, Kosenti A, Kulaksizoglu M, Solmaz S, Sokmen, et al. Frequency of metabolic syndrome in hypothyroid patients. Endocrine Abstracts 2009; 20: 97,

19. Haque R, Ferdousi S, Ferdousi SS, Rahman W, Uddin MN, Hoque MM. Metabolic Syndrome in Hypothyroid Patients. Bangladesh Journal of Medical Biochemistry. 2015 Feb 26;7(2):57-61.

20. Ruhla S, Weickert MO, Arafat AM, Osterhoff M, Isken F, Spranger J, et. al. A high normal TSH is associated with the metabolic syndrome. Clinical Endocrinology. 2010 May 1;72(5):696-701. 